\title{
Design for Reliability of Power Electronics for Grid-Connected Photovoltaic Systems
}

\author{
Yongheng Yang, Ariya Sangwongwanich, Frede Blaabjerg
}

\begin{abstract}
Power electronics is the enabling technology for optimizing energy harvesting from renewable systems like Photovoltaic (PV) and wind power systems, and also for interfacing grid-friendly energy systems. Advancements in the power semiconductor technology (e.g., wide band-gap devices) have pushed the conversion efficiency of power electronics to above $98 \%$, where however the reliability of power electronics is becoming of high concern. Therefore, it is important to design for reliable power electronic systems to lower the risks of many failures during operation; otherwise will increase the cost for maintenance and reputation, thus affecting the cost of PV energy. Today's PV power conversion applications require the power electronic systems with low failure rates during a service life of 20 years or even more. To achieve so, it is vital to know the main life-limiting factors of power electronic systems as well as to design for high reliability at an early stage. Knowhow of the loading in power electronics in harsh operating environments (e.g., fluctuating ambient temperature and solar irradiance) is important for life-time prediction, as the prerequisite of Design for Reliability (DfR). Hence, in this paper, the technological challenges in DfR of power electronics for grid-connected PV systems will be addressed, where how the power converters are stressed considering real-field mission profiles. Furthermore, the DfR technology will be systematically exemplified on practical power electronic systems (i.e., gridconnected PV systems).
\end{abstract}

Index Terms-Reliability, design for reliability, power electronics, physics of failure, mission profiles, thermal loading, degradation, Monte Carlo method, photovoltaic systems.

\section{INTRODUCTION}

A ccessibility and sustainability are of high concern in energy sectors across the globe. Shortage of conventional coalor oil-fired energy and its impact on climate changes have been the main driving forces to develop and advance the renewable energy technology. As of the end of 2015, the total renewable energy installed worldwide is approach-

Manuscript received December 10,2016.The authors hereby confirm that this manuscript has been solely submitted to CPSS TRANSACTIONS ON POWER ELECTRONICS AND APPLICATIONS. Parts of the case study results will be presented at the IEEE Annual Applied Power Electronics Conference and Exposition (APEC 2017), Tampa, FL, USA, Mar. 26-30 2017. Beyond that, the contribution of this paper has not been published in any forms of publications (journals, media, and seminars) prior to this submission.

The authors are with the Department of Energy Technology, Aalborg University, 9220 Aalborg, Denmark (e-mail: yoy@et.aau.dk; ars@et.aau.dk; fbl@et.aau.dk).

Digital Object Identifier 10.24295/CPSSTPEA.2016.00009 ing $2000 \mathrm{GW}$ [1], and the capacity is expected to be even higher in the future [2]. Fig. 1 shows the historical data of the energy paradigm shift to renewables, where it can be observed that the hydropower is always leading in terms of total installed capacity, followed by wind and solar energy. Hydroelectric power systems are deemed as a relatively matured technology that uses released water to spin a turbine for electricity generation. Power electronics is the link of this energy conversion chain. Along with the demand of environmental-friendly energy systems and the decrease of manufacturing cost in wind turbines and solar Photovoltaic (PV) panels, power generation based on wind turbine and PV technologies is becoming increasingly important in national strategical plans, as indicated in Fig. 1. For instance, in Denmark, a goal of completely being independent from fossil fuels by 2050 has been set up [3]. Although there are several state-ofthe-art wind turbine technologies (e.g., the Doubly-Fed Induction Generator - DFIG wind power systems), power electronics converters are normally heavily involved [2],[4],[5]. A thriving penetration of power electronics has also been acknowledged in PV applications, either in small-scale stand-alone units or in large-scale on-grid systems [6],[7]. In a word, power electronics is essential in the power conditioning of renewable energies, and it is also developing with new and emerging power devices coming out on market [8]-[10].

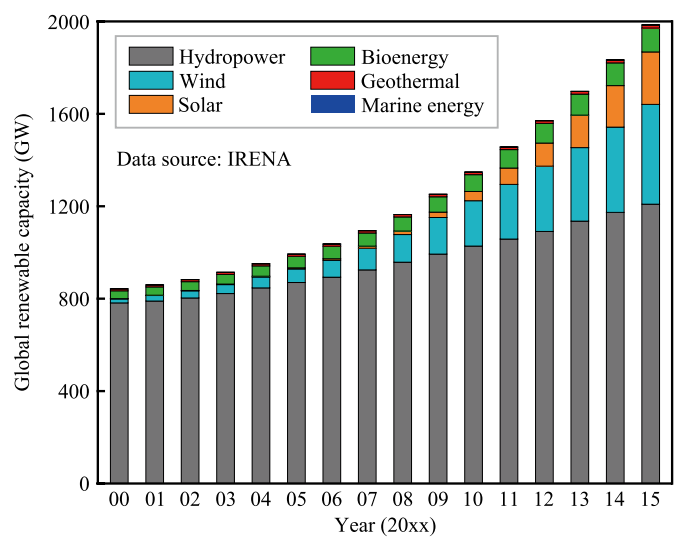

Fig. 1. Annual evolution of the global installed renewable capacity (20002015), where hydropower also includes pumped storage and mixed plants and marine energy covers tide, wave, and ocean energy [1].

To accomplish those objectives, two main challenges have to be addressed: increasing the energy conversion efficiency and reducing the cost in installation and maintenance, which are closely related to the Levelized Cost of Energy (LCOE) [5], [11], [12] as indicated by 


$$
\mathrm{LCOE}=\frac{C_{\mathrm{Int}}+C_{\mathrm{Cap}}+C_{\mathrm{O \& M}}}{E_{\text {Annual }}}
$$

with $C_{\text {Int }}$ being the initial development cost, $C_{\text {Cap }}$ representing the capital cost, $C_{\mathrm{O} \& \mathrm{M}}$ indicating the operational and maintenance cost, and $E_{\text {Annual }}$ is the average annual energy production in the lifetime cycle of the system. Only when the LCOE for renewable energies reaches a comparably low level (i.e., making solar energy cost-competitive), a complete phasing-out of conventional fossil-based energy resources can possibly be realized. This can also be concluded from the SunShot Initiative [13] to lower PV cost by 2030, which is presented in Fig. 2. It can be observed in Fig. 2 that a significant reduction by more than $50 \%$ in the cost of PV systems has been achieved in the past 7 years. More important, the reduction needs to continue. Nevertheless, reflected by (1), the two aforementioned factors affect the LCOE. Namely, increasing the efficiency will contribute to more energy yield, and improving the reliability will lower the cost in maintenance, leading to a lower LCOE. As the power electronics is the core of renewable power generation, highly efficient and highly reliable power electronics converters are thus demanded.

Efficiency improvements can be attained mainly by two means: topological developments and power semiconductor advancements. From the topological point view, reducing the number of conversion stages in PV applications can contribute to an increased efficiency. Transformerless PV inverters are typical representatives in terms of high efficiency, where namely bulky transformers have been removed [7], [14]-[17]. However, topological simplification also brings side-effects like a lack of galvanic isolation, and thus dedicated control strategies are required. Alternatively, latest advancements in power electronics semiconductor technologies (e.g., wide-band gap power devices like Silicon-Carbide - SiC and Gallium-Nitride $\mathrm{GaN}$ transistors), featuring with high-temperature and highswitching-frequency operation capabilities but low power losses, bring much space to improve the efficiency of PV power converters [9], [17]-[21]. As reported, highpower PV converters employing wide-band gap devices have achieved an efficiency approaching 99\% [22], [23]. With this impressive performance, commercial PV inverters (e.g., from GE and SMA) are available on market. In addition, applying the soft switching techniques can also bring down the power losses due to fast switching, and thus in return the overall efficiency can further be improved.

Nevertheless, higher efficiencies of PV converters are relatively achievable, and thus it enables an efficient energy conversion from solar PV panels, especially with the successful applications of wide band-gap devices. However, the power electronics converter itself also becomes one of the most fragile parts in PV systems, leading to many downtimes. According to a survey [24], the unscheduled maintenance events due to power electronics accounts for $37 \%$ of the total events, as it is shown in Fig. 3. Those downtime events require human intervention (system repairing or maintenance), thus affecting the overall production and also increasing the maintenance costs, which can be observed in Fig. 3. In the end, the LCOE of PV energy according to (1) will go up drastically due to the high failure rate of power inverters in PV systems. Hence, as aforementioned, high reliability of power electronics is in urgent need on top of efficiency.

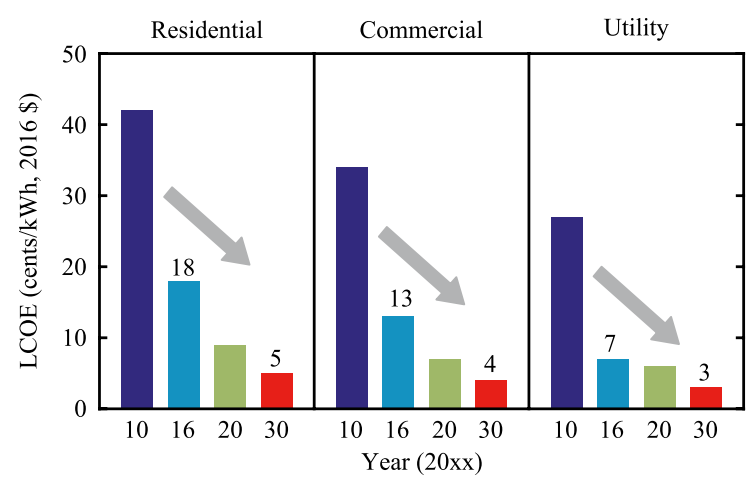

Fig. 2. Progress and goals of the SunShot Initiative to lower the cost of PV systems in residential, commercial, and utility applications [12], [13]. Figure adapted from the National Renewable Energy Laboratory (NREL).

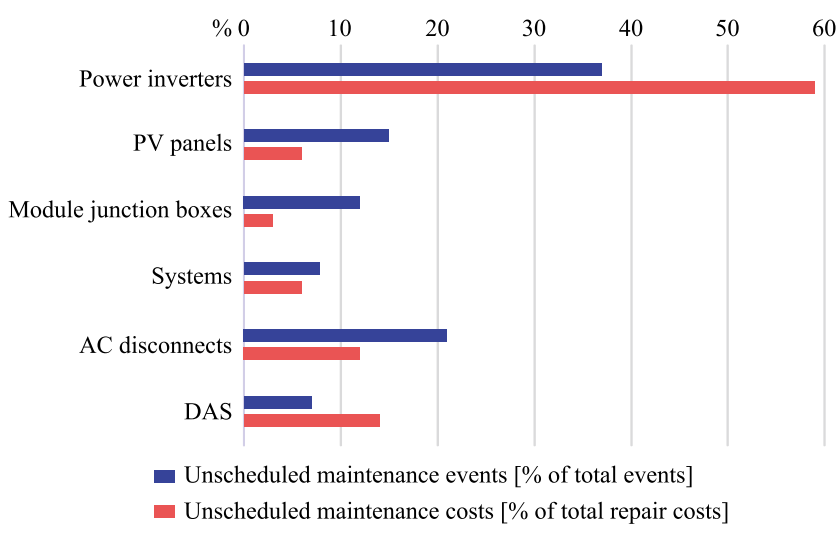

Fig. 3. Five year of real-field experience in failures of an utility-scale PV power plants [24], where DAS stands for Data Acquisition Systems.

In regards to enhancing reliability, more challenging issues have to be addressed [25]-[35]. It is very important to predict the lifetime, and thus Design for Reliability (DfR) can be incorporated in the design phase of the PV inverter system considering key life-limiting aspects [36], [37]. Previous research in lifetime prediction of power electronics (converters) has been mainly focused on statistic analysis. During this period, a handbook - MIL-HDBK-217 $\mathrm{F}$ [38] has been widely adopted to predict the lifetime of electronics equipment [32], [37], [39]-[43]. Basically, the lifetime predication can be achieved in a statistic way, where the reliability models (typically, constant failure rates) of subsystems are defined. Various analysis approaches like fault tree analysis [44], [45], Markov analysis [32], [46]-[49], failure mode and effect analysis [50], [51], and reliability block diagram analysis [52] can then be employed to determine the reliability from a systemlevel viewpoint. 
However, the models with constant failure rates in this handbook are out of date, which have not been updated since 1995, leading to the revocation of this handbook. Another reason for the termination is that the predicted lifetime or reliability has no direct or high guiding value for planning and design of the entire PV systems [39]. That is, it is difficult to use the predicted reliability data to design new products or systems with higher reliability.

Hence, a transition to the Physics-of-Failure (PoF) based reliability analysis is undergoing [25], [26], [30], [33], [53], where identifying the root-causes of failures in power electronics is one of the attempts. In addition, for the PoF reliability analysis, different failure mechanisms from the points of view of physical structure, internal material characteristic, and operational environment/condition in power electronics are studied in prior-art research [35], [53]-[66]. Among those investigations, it has been observed that the thermo-mechanical stress is one major inducers of failures (mainly die-attach solder crack and bond-wire damage). The thermal stress is reflected as temperature cycling in the power electronics devices, including mean junction temperatures and junction temperature swings. Therefore, many attempts have been made to estimate the junction temperature in real-time [67]-[69] and develop schemes to manage/control the junction temperature for higher reliability [70]-[72]. In practice, the temperature variations are closely related to the operating conditions and environments, which are referred to as mission profiles [73][76]. Hence, the reliability analysis of power electronics in PV applications should also involve the acknowledge of mission profiles (i.e., ambient temperature and solar irradiance), which are time-varying inputs. In all, it calls for a systematic reliability analysis and design approach for power electronics in PV applications. It should be pointed out that enhancing the redundancy of PV power converters may also contribute to a high reliability at the cost of complexity.

In light of the above concerns, this paper briefly discusses the mainstream power electronics converters for gridconnected PV systems in $\S$ II. More important, reliability analysis in grid-connected PV inverters has been performed, where the DfR approach has been demonstrated in $\S$ III. A case study on a 6-kW single-phase grid-connected PV inverter system has been provided in $\S$ IV to better illustrate the DfR approach considering mission profiles, where the Monte-Carlo based simulation has also been performed so that a systemlevel reliability analysis can be achieved. It is demonstrated that the mission profile is an important factor which should be taken into account in the design phase of power electronics converters. Fortunately, the presented DfR approach offers a systematical design. Finally, $\S \mathrm{V}$ gives concluding remarks and also discusses future research trends in the reliability of power electronics.

\section{Power Converters for PV Systems}

Power electronics converters are the link between solar
PV energy and the grid, and thus have to perform various rigorous functions [5]. Harvesting and then transferring the solar PV energy to an ac grid considering the inherent characteristic of intermittency are the basic requirements. Also, other specifications are imposed to make gridconnected PV systems more resilient and grid-friendly: 1) reliable or secure the power supply, 2) flexible control of active and reactive power, 3) dynamic grid support per demands, 4) system condition monitoring, protection and communication, and 5) high efficiency and reliability, low cost, and small volume. Practically, there are mainly four structures for grid-connected PV systems, as it is shown in Fig. 4. It is clearly observed in Fig. 4 that the intermediate unit-power electronics converters is of essence to the energy conversion, in which the above functions should be implemented.

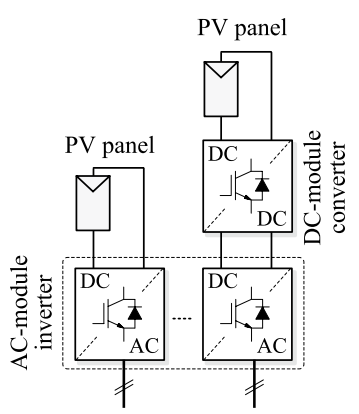

(a)

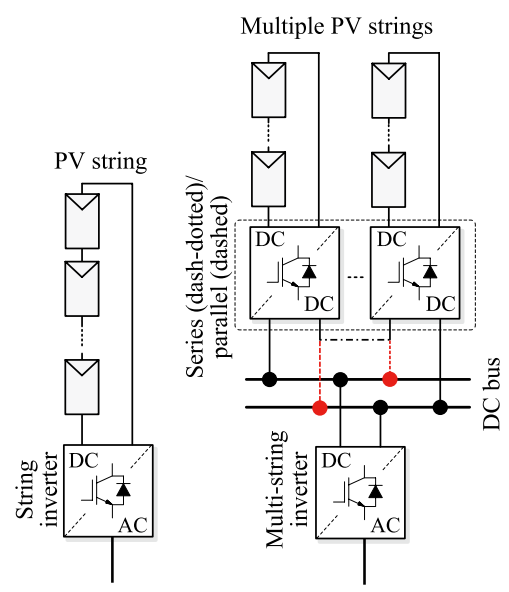

(c)

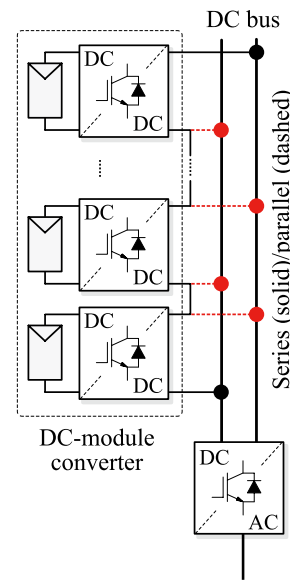

(b)

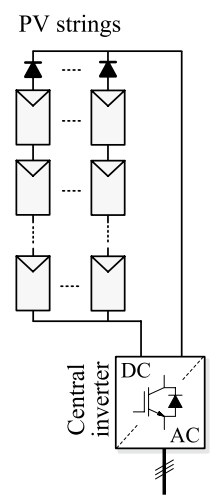

(d)
Fig. 4. Grid-connected PV system configurations: (a) module converters typically applied in single-phase small systems of hundred watts, (b) dcmodule converters connected to a common dc-bus (forming a dc-grid), which can be connected to grid as single- or three-phase systems of several $\mathrm{kW}$ in small or residential applications, (c) string and multi-string converter applied in single- or three-phase systems (residential and commercial applications), and (d) center inverters for commercial or utility scale applications (high power, e.g., hundred kW).

Depending on the applications and power ratings, a PV system can be configured according to Fig. 4. For instance, 
modular PV converters (Fig. 4(a) and (b)) are commonly adopted in small energy conversion systems, where volume and scalability are important. However, in order to connect modular PV converters to the grid through an inverter, high conversion ratio dc-dc converters may be required or a dcgrid is necessary. Comparing to this, string, multi-string or central inverters can directly feed power into the grid, as demonstrated in Fig. 4(c) and (d). In fact, the PV utilization is still at a residential level but tends to be large-scale with increased power ratings. Hence, string and multi-string inverters are dominate on market, and the single-phase connection is more often to see [7], [77]. Fig. 5 exemplifies a single-phase grid-connected PV system with an LCL filter, where a full-bridge inverter has been employed. Additionally, to have a higher efficiency, transformerless PV inverters are favorable, as shown in Fig. 5. However, the removal of isolation transformers can generate leakage currents in the system, which may be addressed by specifically designing the modulation schemes [5], [14].

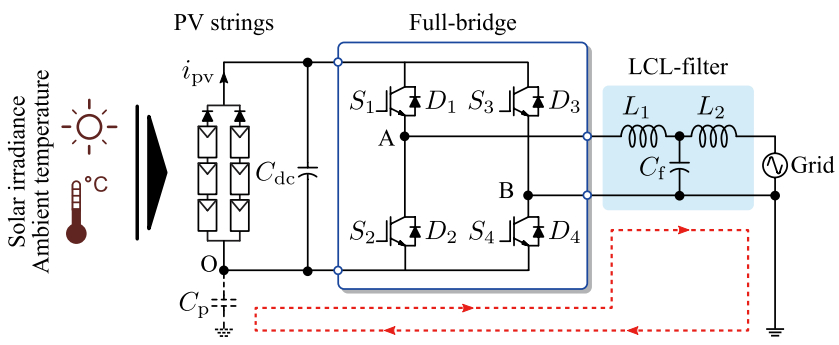

Fig. 5. Single-phase single-stage transformerless full-bridge string inverter with an LCL filter, where ipv represents the PV output current and $C_{\mathrm{p}}$ is the parasitic capacitor between the PV panels (strings) and the ground. The red dashed line indicates possible leakage currents circulating through the parasitic capacitor $C_{\mathrm{p}}$.

Although single-phase grid-connections are more commonly seen in PV applications, increasing demands in power push the rating of PV systems higher. In that case, three-phase PV systems with central inverters become feasible, which is also promoted by industrial companies like SMA, ABB, and Kaco. For high-power utility-scale PV systems, the power electronics converters can be traditional full-bridge converters, as shown in Fig. 6. Notably, the cables and power devices may have to bear large currents. Disconnecting a large amount of $\mathrm{dc}$ currents is also challenging. As an alternative, (modular) multilevel converters might be a promising solution [78]-

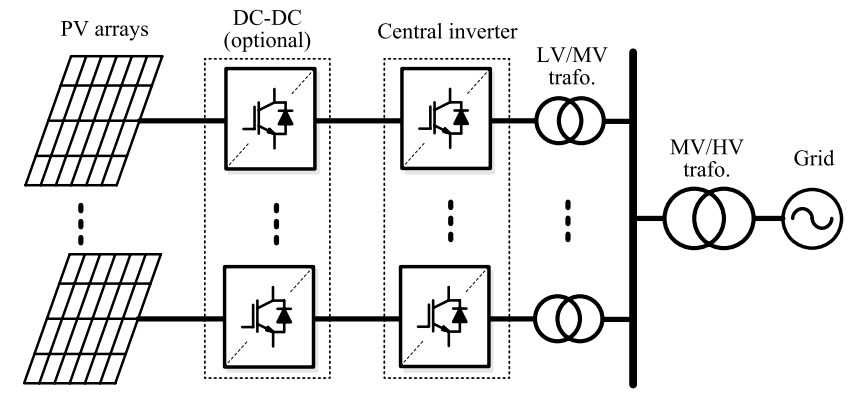

Fig. 6. Connecting large-scale PV plants to the grid through center inverters, where the dc-dc converters are optional.
[80]. Nevertheless, the role of power electronics converters remains in high-power applications.

\section{Design for Reliability of Power Converters for PV SYSTEMS}

As discussed in $\S$ II, PV panels and power converters are essential components, but all have to be considered in the design phase in order to further break down the cost of PV energy. Fig. 7 shows the cash-flow in the design and operation phases of grid-connected PV systems, where it can be observed that many factors affect the cost of PV systems. Furthermore, it is implied that the unexpected failures during operation incur high costs in maintenance [36]. This is because the reliability is not specifically included in the design, but reflected as slow and expensive feedbacks or iterations.

Hence, in order to lower the unscheduled maintenance cost, potential failures should be anticipated as early as possible and input in the design. This initiates a more promising solution to improving the reliability of PV systems, as it is shown in Fig. 8. The inclusion of the DfR enables a quick identification of design flaws or weakness, and thus feeds back to the design for corrections (e.g., re-selection of components). After a few iterations, the reliability demands can be fulfilled before the system construction. Consequently, it contributes to significant cost reduction in the design phase and shorter development cycle for the PV system targeting for higher reliability. Furthermore, the failures or downtimes of the PV systems are predictable.

Notably, the DfR approach is relying on the lifetime or reliability prediction, which involves in multiple disciplines from the PoF point of view. Fig. 9 depicts the detailed reliability evaluation process of the DfR approach. It can be seen that the reliability analysis has three major tasks: 1) failure identification, 2) stress analysis and strength modeling, and 3) reliability mapping. More specific, the critical components and the major failure mechanisms in the PV power converter system are identified through physics analysis and real-field experience. Accordingly, the corresponding stresses and the ability of power electronics components to withstand the stresses are tested and modeled. Finally, counting algorithms and statistical distributions are adopted to map the stress and strength information of the power electronics components to the reliability metrics of the entire PV power converter. Notably, the reliability indicators can be direct performances like $B_{x}$ lifetime, robustness, and failure probability, etc., or indirect performances like maximum thermal stress [36].

For a specific application (e.g., the PV inverter installed in Denmark), the DfR approach included in the design phase of Fig. 8 and detailed in Fig. 9 enables analyzing the power converter candidates in terms of reliability. Here, the failure mechanisms have to be identified first. As it has been discussed previously, for power electronics converters, the major failures are related to the temperature in power 


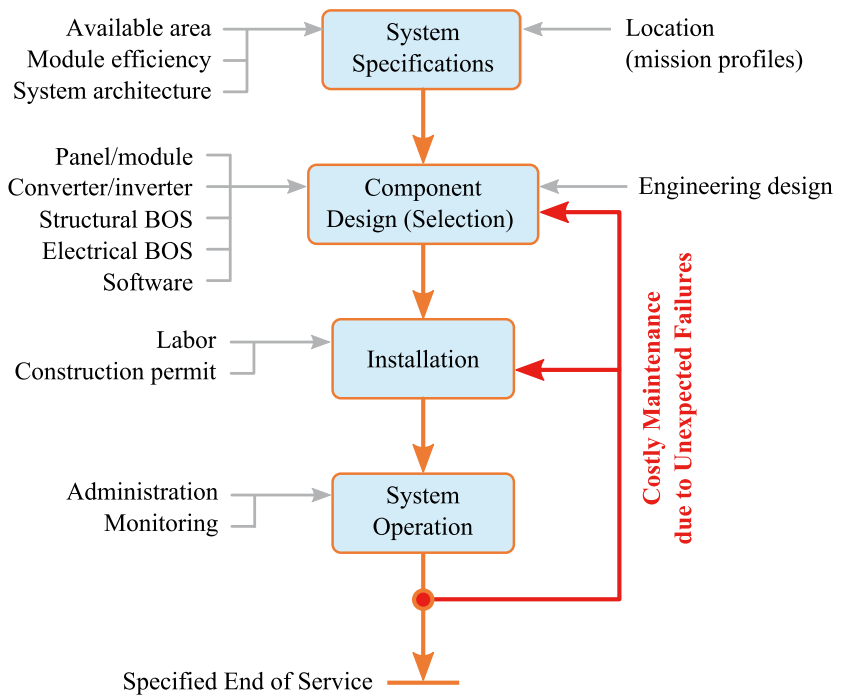

Fig. 7. Cash-flow in the conventional design and operation phases of gridconnected PV systems (BOS - Balance of System).

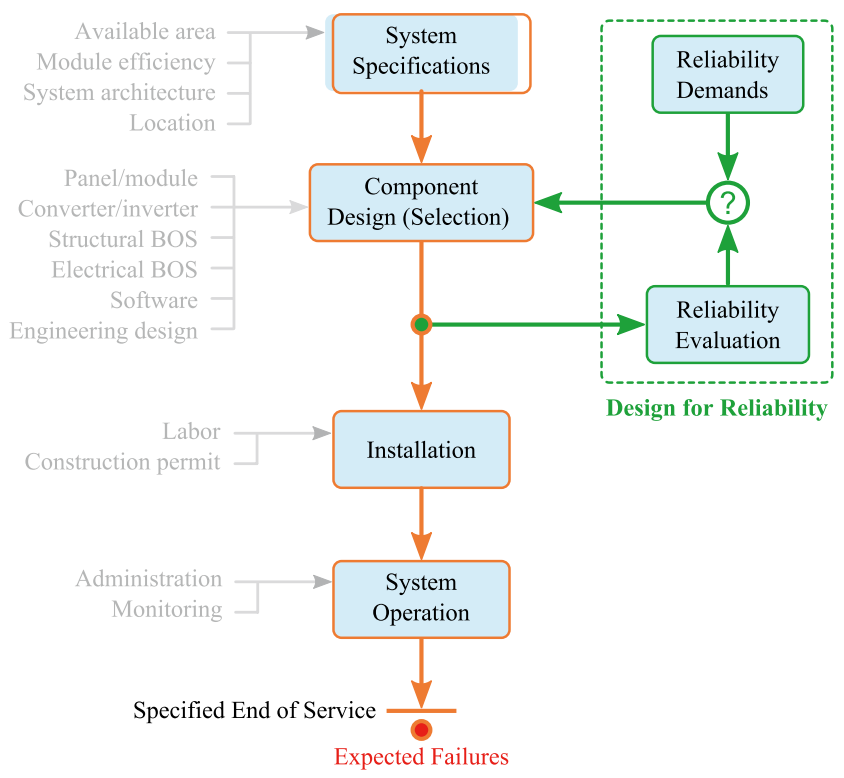

Fig. 8. Cash-flow in the design and operation phases of grid-connected PV systems, where the design for reliability of power electronics has been incorporated in the design phase.

devices. This can also be validated through accelerated tests, where power cycling and thermal cycling should be performed. Nevertheless, on condition that the failure mechanisms are identified, it is possible to directly translate mission profiles specified by customers into thermal loading on the power electronics components of the selected candidates according to Fig. 9. As a result, the reliability is obtained from a system point view, and the process is summarized as:

- Mission profile translation to thermal loading

- Thermal cycling interpretation

- Lifetime (degradation) model of power devices

- Monte Carlo reliability assessment

- System-level reliability analysis

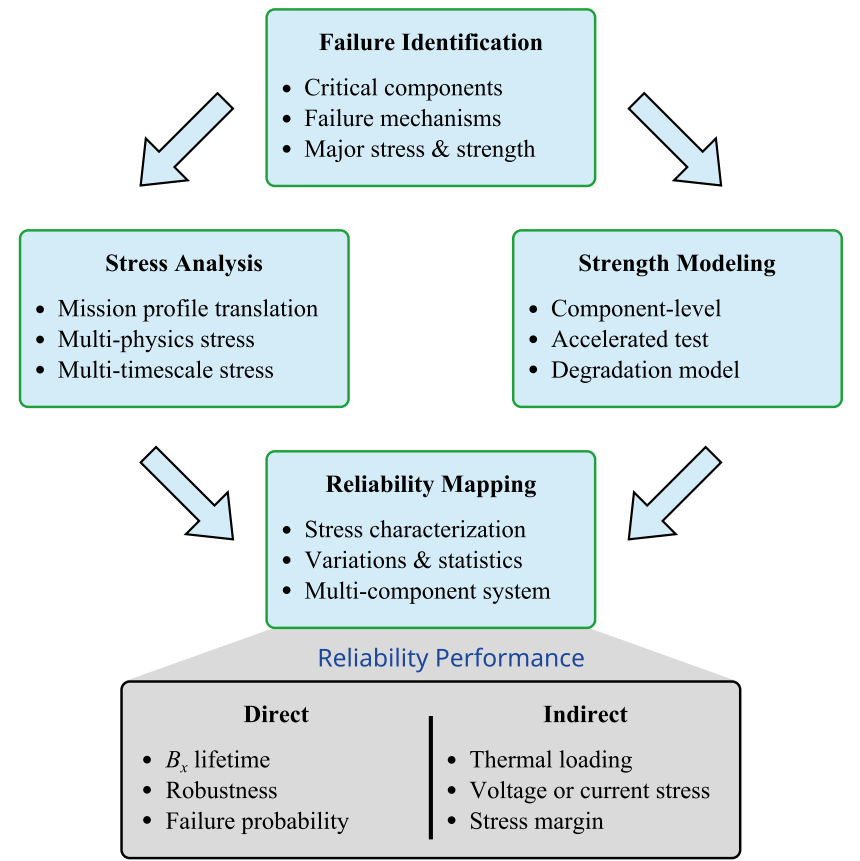

Fig. 9. Design for Reliability (DfR) structure for power electronics converters, which can be used to evaluate the reliability of candidate power converters considering various factors (e.g., mission profiles). In this approach, $B_{x}$ lifetime indicates the time by which $x$ percent of a population of the evaluated system will have failed.

which will be discussed in details as following.

\section{A. Mission Profile Translation to Thermal Loading}

In the DfR approach, the knowledge of the power converter operating conditions during the entire operation is essential [25], [73], [75]. In this respect, a mission profile of the power converters, which represents the operating condition of the system, is needed. The mission profile of the PV system can be obtained from the solar irradiance and ambient temperature profiles at the installation sites, as these two parameters have a strong impact on the PV power production [76]. Then, the mission profiles have to be translated into thermal loading of power converters (e.g., junction temperature variations of the devices), since it is usually a life-limiting factor in power electronic applications (e.g., resulting in a bond wire lift-off) [60]. There are intermediate steps to obtain the thermal loading of the power converters, as it is illustrated in Fig. 10.

From the solar irradiance and ambient temperature profiles, the PV power production $P_{\mathrm{pv}}$ can be estimated from the PV panels electrical characteristic model [81]. Then, by taking the MPPT algorithm efficiency $\eta_{\mathrm{MPPT}}$ and the PV inverter electrical characteristic (e.g., conduction and switching behaviors of power devices) into account, the power losses dissipated in the power devices $P_{\text {loss }}$ can be estimated. Notably, this loss calculation is usually implemented with a Look-Up Table (LUT), in order to assist the long-term simulation (e.g., an annual mission profile). In that case, the power losses are calculated for a certain set of operating conditions (e.g., the input power from $0 \%$ to 


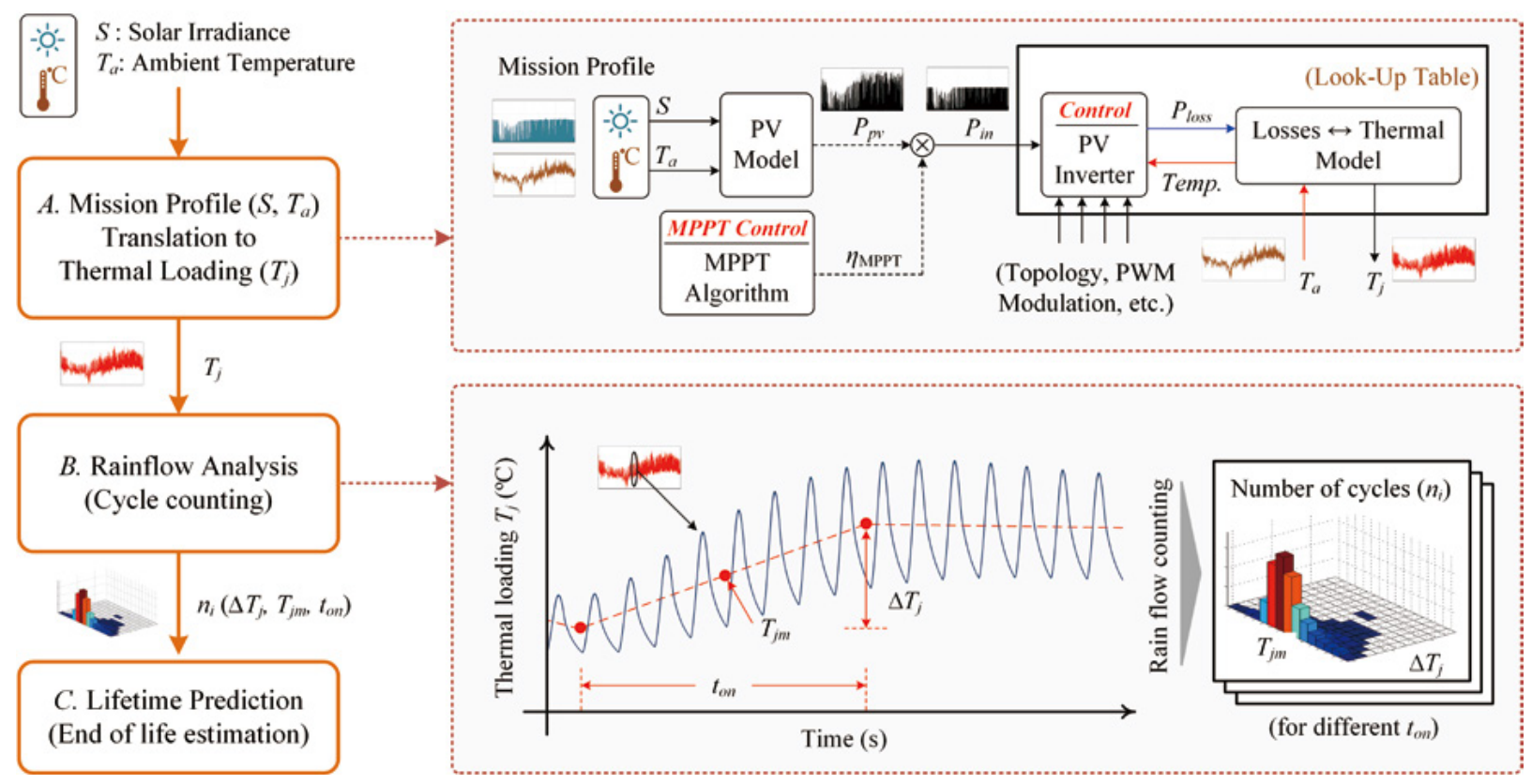

Fig. 10. Flowchart of the lifetime evaluation or predication considering mission profiles of the power electronics systems [76].

$100 \%$ of the rated power, and the ambient temperature from $-25^{\circ} \mathrm{C}$ to $50{ }^{\circ} \mathrm{C}$ ), and the power losses under other operating conditions can be interpolated from the constructed LUT. Then, the thermal model of the power devices in the power converter is needed in order to obtain the device junction temperature variation due to the dissipated power losses in the power devices.

\section{B. Thermal Cycling Interpretation}

By applying the previous process, the junction temperature of the power device $T_{j}$ under a specific mission profile can be obtained. However, the device junction temperature is usually an irregular loading profile, due to the dynamics of mission profiles (i.e., solar irradiance and ambient temperature for gridconnected PV systems). Thus, a cycle counting algorithm such as a rainflow analysis is usually employed, in order to divide the irregular thermal loading cycle into several regular thermal loading cycles [82]. By doing so, the information such as the mean junction temperature $T_{j m}$, the cycle amplitude $\Delta T_{i}$, and the cycle period $t_{o n}$ can be obtained, which can be then applied to the lifetime (degradation) model of the power electronics devices of the converter candidates.

\section{Lifetime (Degradation) Model of Power Devices}

There are several components in the PV inverter (e.g., capacitors and IGBTs) that can cause failure of the system. In that regards, it leads to a complex analysis, as the components in the inverter systems may have a cross effect of the reliability on each other. In this study, only the temperature-related failure mechanisms of the power device are considered in order to simplify the reliability analysis. In fact, the power device has been reported as one of the most critical components in the power converter, which cause failures of the whole system [27]. Hence, there are many temperature-related lifetime models reported in literature [61], [83]. According to [61], a lifetime model of an IGBT power device can be given as

$$
\begin{aligned}
N_{f}= & A \times\left(\Delta T_{j}\right)^{\alpha} \times(a r)^{\beta_{1} \Delta T_{j}+\beta_{0}} \times\left[\frac{C+\left(t_{o n}\right)^{\gamma}}{C+1}\right] \\
& \times \exp \left(\frac{E_{a}}{k_{b} \times T_{j m}}\right) \times f_{d}
\end{aligned}
$$

where $N_{f}$ is the number of cycles to failure [61]. Notably, the inputs of this lifetime model are: the mean junction temperature $T_{j m}$, cycle amplitude $\Delta T_{j}$, and cycle period $t_{o n}$, which can be obtained from the cycle counting process, while the other parameters are given in TABLE I. Normally, the lifetime of the power device is expressed by considering the Life Consumption (LC), which indicates how much life of the device has been consumed (or damaged) during operations. The LC is calculated by using the Miner's rule as [82]

$$
\mathrm{LC}=\sum_{i} \frac{n_{i}}{N_{f i}}
$$

TABLE I

Parameters of the Lifetime Model of an IGBT Module [61].

\begin{tabular}{cll}
\hline \hline Parameter & \multicolumn{1}{c}{ Value } & Experimental condition \\
\hline $\mathrm{A}$ & $3.4368 \times 10^{14}$ & \\
$\alpha$ & -4.923 & $64 \mathrm{~K} \leqslant \Delta T_{j} \leqslant 113 \mathrm{~K}$ \\
$\beta_{1}$ & $-9.012 \times 10^{-3}$ & \\
$\beta_{0}$ & 1.942 & $0.149 \leqslant a r \leqslant 0.42$ \\
$C$ & 1.434 & $0.07 \mathrm{~s} \leqslant t_{\text {on }} \leqslant 63 \mathrm{~s}$ \\
$\gamma$ & -1.208 & \\
$f_{d}$ & 0.6204 & $32.5{ }^{\circ} \mathrm{C} \leqslant T_{j} \leqslant 122{ }^{\circ} \mathrm{C}$ \\
$E_{a}$ & $0.06606 \mathrm{eV}$ & \\
$k_{B}$ & $8.6173324 \times 10^{-5} \mathrm{eV} / \mathrm{K}$ & \\
\hline \hline
\end{tabular}


where $n_{i}$ is the number of cycles (obtained from the thermal cycling interpretation, e.g., a rainflow analysis) for a certain $T_{j m}, \Delta T_{j}$, and $t_{o n}$, and $N_{f i}$ is the number of cycles to failure calculated from (2) at that specific stress condition. For instance, if the number of cycles $n_{i}$ is counted from a oneyear mission profile, the LC calculated in (3) will represent a yearly $\mathrm{LC}$ of the power device. When the LC accumulates to unity (i.e., 100\%), the power electronics device is considered to reach its end of life, and the lifetime can be predicted.

\section{Monte Carlo Reliability Assessment}

Actually, the lifetime prediction of the power device obtained from (3) can be considered as an ideal case, where all the power devices fail at the same rate (under a certain mission profile). In reality, there are uncertainties in the timeto-failure of the power devices, which are mainly introduced by variations in the lifetime model parameters as well as variations in the stresses. Therefore, it is more common to express to lifetime prediction in terms of statistical value (e.g., by using probability of failure), rather than the fixed value. In order to do so, the Monte Carlo analysis needs to be performed. The idea of the Monte Carlo method is to introduce variations in the system parameters, and simulate the result with a large number of samples. With the large enough number of samples, the results will converge to the expected value.

This approach can be employed for estimating the power devices lifetime [62], [84], [85], as it is shown in Fig. 11. In this method, all the parameters in the lifetime model in (2) have to be modeled by a distribution function (e.g., normal distribution) with a certain range of variations. Then, following the Monte Carlo simulation approach, a certain number of samples from each parameter distribution are randomly taken for calculating the lifetime of the power device. By doing so, a set results of lifetime prediction is obtained, which can then be represented with a certain distribution function (e.g., Weibull distribution) [86]. The Probability Density Function (PDF) of this lifetime prediction result is usually referred to as a lifetime distribution (failure distribution) $f(x)$, while its Cumulative Distribution Function (CDF) is considered as an unreliability function $F(x)$. The $B_{x}$ lifetime, which is the time when $x \%$ of the populations are failed, can be obtained from the unreliability function of the power device, as it is shown in Fig. 11.

\section{E. System-Level Reliability Analysis}

In most cases, the power converters consist of several power devices, where each device has its own unreliability function $F(x)$. In order to perform the system-level reliability assessment, the reliability block diagram of the whole system needs to be constructed [28]. The reliability block diagram represents how the reliability of components in the system interact with each other. For the system with $n$ number of components and the system cannot function if

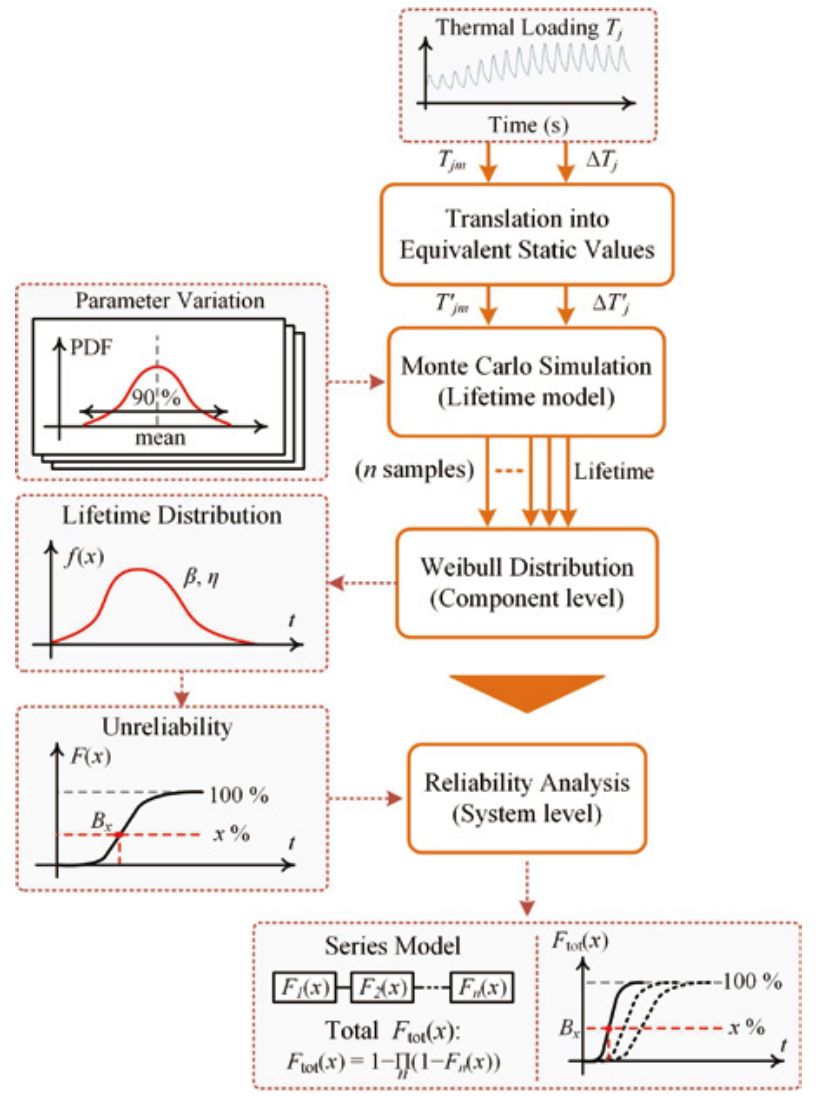

Fig. 11. Flow diagram of Monte Carlo-based system-level reliability assessment of PV inverters with reliability block diagram.

any of the component fails, the total unreliability of system $F_{\text {tot }}(x)$ can be calculated as:

$$
F_{\text {tot }}(x)=1-\prod_{n}\left(1-F_{n}(x)\right)
$$

where $F_{n}(x)$ is the unreliability function of the $n^{\text {th }}$ component. Once the total unreliability function of the inverter system $F_{\text {tot }}(x)$ is obtained, the $B_{x}$ lifetime of the entire PV inverter can be estimated in the similar way as it has been done for a single power electronics component.

It should be pointed out that this approach can be applied to any power electronic system. For different converter topologies, the reliability block diagram of the system may be different, depending on the number of power devices and their operational principle.

\section{CASE STUdY}

In this section, a case study of $6 \mathrm{~kW}$ single-phase PV inverters will be presented. The DfR approach discussed in $\S$ III will be applied to the mission profile of the inverter installed in Denmark. The lifetime evaluation and the reliability assessment will be carried out in the following.

\section{A. Mission Profiles of the Case Study}

The yearly solar irradiance and ambient temperature profiles recorded from the installation site in Denmark are 
shown in Fig. 12. It can be seen from Fig. 12(a) that the solar irradiance level varies considerably through the whole year. The average solar irradiance level is relatively high from June through August, while it is relatively low through November to February. This variation in the solar irradiance during the year will have a direct impact on the PV power production, which will in return contribute to the long-term thermal loading of the power devices in the PV inverter.

Similarly, the ambient temperature in Denmark also varies in a wide range during the year. For instance, the highest temperature reaches around $34{ }^{\circ} \mathrm{C}$ in summer (i.e., at the end of May), while the lowest ambient temperature can be around $-18{ }^{\circ} \mathrm{C}$ in winter (i.e., at the beginning of February). This ambient temperature variation will have a strong influence on the mean junction temperature, but also contribute indirectly to the thermal loading of the PV inverter through the life-cycle $\mathrm{PV}$ power production.

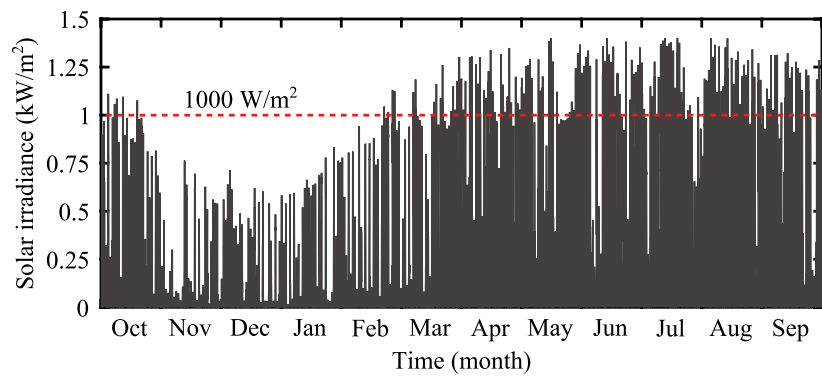

(a)

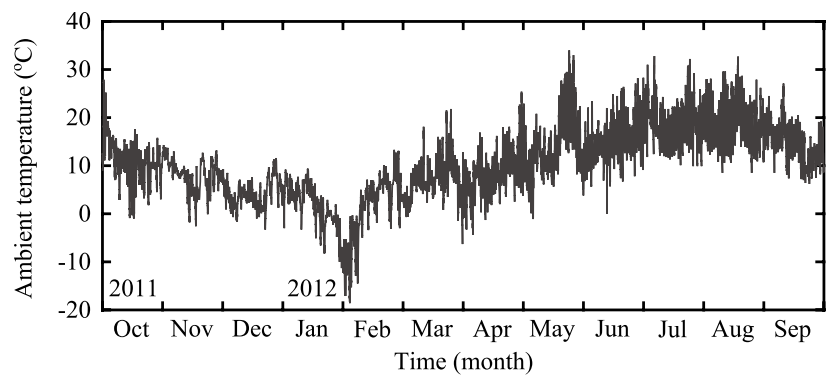

(b)

Fig. 12. Yearly mission profiles (i.e., irradiance and ambient temperature with a sampling rate of 5 mins per sample) in Denmark: (a) solar irradiance level and (b) ambient temperature.

\section{B. Translated Thermal Loading}

By using mission profile translation process presented in $\S$ III.A, the junction temperature of the power device can be obtained. The power device junction temperature of the PV inverter installed in Denmark (with the mission profile in Fig. 12) is presented in Fig. 13. It can be seen that the cycle amplitude of the junction temperature in Fig. 13(a) has similar variations as the solar irradiance profile in Fig. 12 (a), with the maximum cycle amplitude of $25^{\circ} \mathrm{C}$. The mean junction temperature of the power device is shown in Fig. 13(b), which has a similar tendency as the ambient temperature profile. The mean junction temperature reaches its highest value at $78^{\circ} \mathrm{C}$, while its minimum value is $-18^{\circ} \mathrm{C}$ in winter (i.e., at the beginning of February).

\section{Lifetime Evaluation}

The rainflow analysis is then applied to the junction temperature loading profile shown in Fig. 13, and the results are used to determine the LC from the lifetime model in (2). By doing so, the resultant LC for a single device of the PV inverter can be calculated as 0.0073 year, which indicates that the individual power semiconductor device will reach its end of life after 137 years of operation.

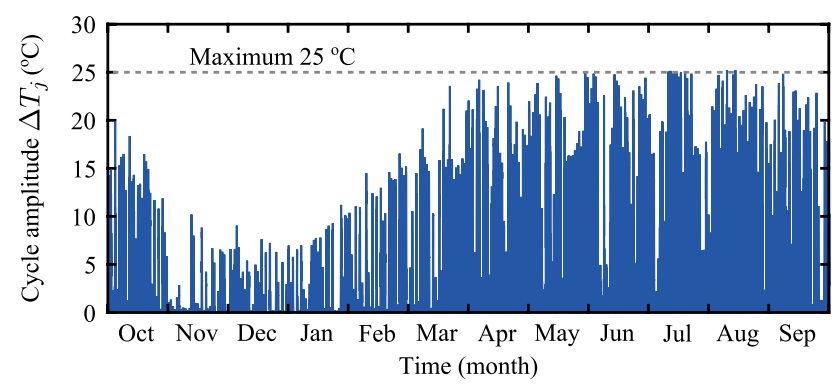

(a)

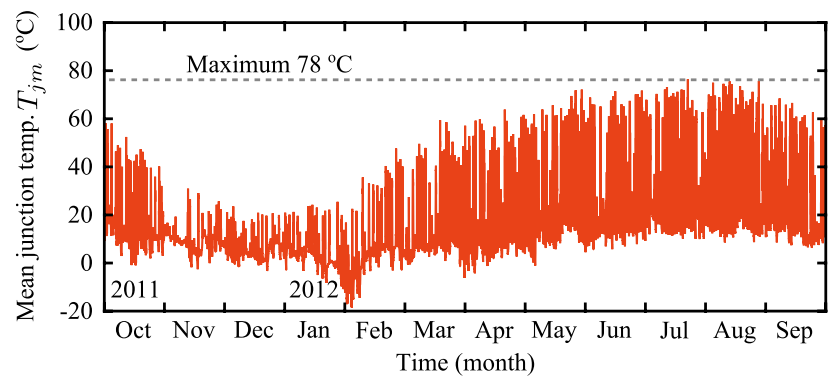

(b)

Fig. 13. Thermal loading of an individual power device in the singlephase full-bridge PV inverter under a yearly mission profile in Denmark (see Fig. 12): (a) cycle amplitude of the junction temperature variation $\Delta T_{j}$ and (b) mean junction temperature $T_{j m}$ of the power device.

Considering parameter variations of the lifetime model, the Monte Carlo method is applied to the lifetime evaluation. In this case, the parameters of the lifetime model in (2) are modeled by using a normal distribution with $5 \%$ parameter variation. Similarly, the parameter variation also needs to be introduced to the stress parameters $\left(T_{j m}, \Delta T_{j}\right.$, and $\left.t_{o n}\right)$, which are the inputs of the lifetime model. In this case, it is necessary to determine the equivalent static value of these dynamic parameters (which dynamically changes during operations, i.e., mission profile). Basically, the equivalent static value of the stress parameters $\left(T_{j m}^{\prime}, \Delta T_{j}^{\prime}\right.$, and $\left.t_{o n}^{\prime}\right)$ are the representative values of the stresses obtained from mission profile, which results in the same LC.

In fact, there are several combinations of equivalent static values that can be applied to the lifetime model and result in the same LC. For simplification, only the line frequency (i.e., $50 \mathrm{~Hz}$ ) thermal cycling is considered, meaning that $t^{\prime}$ on is selected to be $0.01 \mathrm{~s}$ (heating period is half of the total cycle period), and the number of cycles per year $n_{i}^{\prime}$ is $(365 \times 24 \times 60 \times 60) \times 50$ cycles. Regarding the junction temperature variations, the equivalent mean junction temperature $T_{j m}^{\prime}$ can be obtained by averaging the yearly profile of the mean junction temperature in Fig. 13(b). 
Afterward, the equivalent cycle amplitude $\Delta T^{\prime}{ }_{j}$ can be calculated by solving the equation (2). The equivalent static values from the mission profile of the PV inverter installed in Denmark is summarized in TABLE II. Once the equivalent static values are determined, they are also modeled with a normal distribution function, as it has been done previously with the lifetime model parameters.

The Monte Carlo simulation is then carried out with a population of 10000 samples, where the LC and the corresponding lifetime for 10000 samples can be obtained and fitted with a Weibull distribution. Notably, the lifetime distribution of the power device, $f(x)$, usually follows the Weibull distribution [53], [86], whose PDF can be expressed as

$$
f(x)=\frac{\beta}{\eta^{\beta}} x^{\beta-1} \exp \left[-\left(\frac{x}{\eta}\right)^{\beta}\right]
$$

where $\beta$ is the shape parameter and $\eta$ is the scale parameter. In general, the value of $\beta$ represents a failure mode (i.e., same failure modes will result in a similar $\beta$ value), while the value of $\eta$ is corresponding to the time when $63.2 \%$ of population will have failed [53]. The lifetime distribution $f(x)$, Weibull PDF, of the power device obtained from the Monte Carlo simulation is shown in Fig. 14(a), and the unreliability function (Weibull CDF) is shown in Fig. 14(b). From the Weibull CDF in Fig. 14(b), the Bx lifetime of one singledevice power device considering parameter variations can be obtained. For instance, the $\mathrm{B}_{10}$ and $\mathrm{B} 1$ lifetime of the power device are 74 and 42 year, respectively. This implies that $10 \%$ of the population is expected to fail after 74 years of operation, and $1 \%$ of the populations is expected to fail after 42 years.

TABLE II

Equivalent Static Values of the Stress Parameters.

\begin{tabular}{ll}
\hline \multicolumn{1}{c}{ Parameters } & \multicolumn{1}{c}{ Value } \\
\hline Mean junction temperature $T_{j m}^{\prime}$ & $13.45^{\circ} \mathrm{C}$ \\
Cycle amplitude $\Delta T_{j}^{\prime}$ & $5.69^{\circ} \mathrm{C}$ \\
Cycle period $t_{o n}^{\prime}$ & $0.01 \mathrm{~s}$ \\
Number of cycles per year $n_{i}^{\prime}$ & $(365 \times 24 \times 60 \times 60) \times 50$ \\
Yearly LC & 0.0073 \\
Lifetime prediction & 137 years \\
\hline \hline
\end{tabular}

\section{System-Level Reliability Analysis}

From the component-level unreliability function $F(x)$ obtained from the Monte Carlo method, the system-level reliability assessment can be performed by using the reliability block diagram. The full-bridge inverter topology in Fig. 5 consists of four power devices and the inverter cannot function if any of the devices fail. Thus, the total unreliability of system $F_{\text {tot }}(x)$ can be calculated as:

$$
F_{\text {tot }}(x)=1-\prod_{n=1}^{4}\left(1-F_{n}(x)\right)
$$

where $F_{n}(x)$ is the unreliability function of the $n^{\text {th }}$ power device in the system. In the case of full-bridge topology (with bipolar pulse width modulation technique), the loading of each power device is equal, meaning that, it has the same unreliability function: $F(x)=F_{1}(x)=F_{2}(x)=F_{3}(x)=F_{4}(x)$. Therefore, the system-level unreliability function can be simplified as

$$
F_{\text {tot }}(x)=1-(1-F(x))^{4}
$$

The total unreliability of the full-bridge inverter is presented in Fig. 14(b), and the corresponding system-level $B_{x}$ lifetime is also shown in the same figure. The $B_{10}$ and $B_{1}$ lifetime of the full-bridge inverter (i.e., system-level reliability) is 53 and 30 years, respectively, which is 21 and 12 years lower than the component-level $B_{10}$ and $B_{1}$ lifetime.

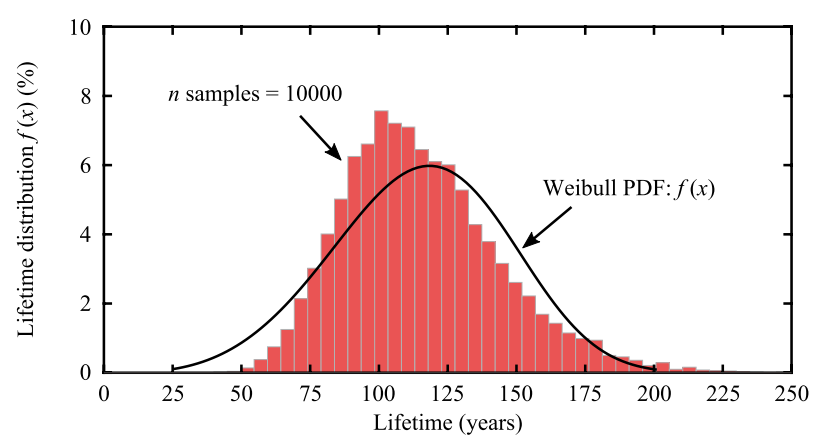

(a)

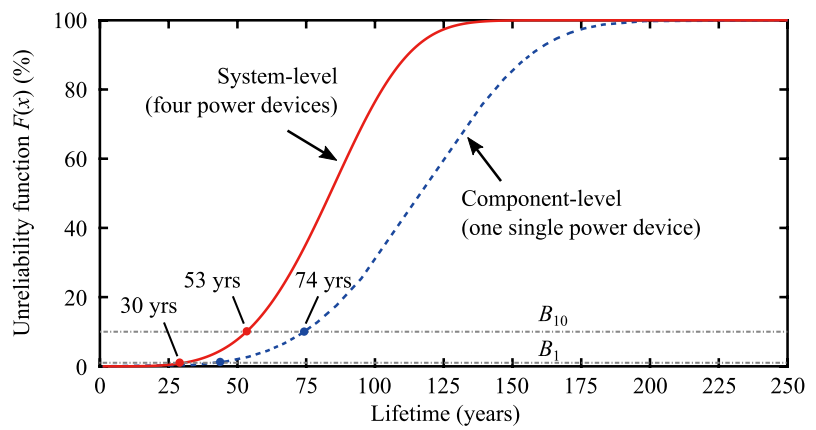

(b)

Fig. 14. Results from the Monte Carlo simulation with 10000 samples: (a) lifetime distribution of one single power device (i.e., the Weibull PDF function) and (b) unreliability function (i.e., the Weibull CDF function) of one single power device (component-level) and full-bridge inverter with four power devices (system-level).

\section{CONCLUSIONS}

In this paper, it has been illustrated that the developments and requirements for the power electronics technology in the grid-connected PV systems are increasing drastically, where the importance of reliability performance should be especially focused. State-of-the-art in power electronics converters for grid-connected PV power generation systems has been briefly presented, where the role of power electronics converters is highlighted. Then, the Design for Reliability (DfR) approach has been introduced in details. A case study on a gridconnected PV system has also been performed to demonstrate the DfR approach.

It is concluded that as the continuously fast development 
of the grid-connected PV technology, the reliability performance of the power electronics in such applications is getting more and more critical. There are many emerging challenges as well as technology opportunities to achieve more reliable power electronics, in such a way that the LCOE in solar PV systems can be further reduced. It is worth to mention that, right now the reliability calculation and analysis for power electronics including PV power converters are undergoing revolutionary advancements, many other issues beside power semiconductors and thermal loading are also important factors to be taken into consideration in the final product.

\section{REFERENCES}

[1] International Renewable Energy Agency (IRENA), "Renewable capacity statistics 2016," Tech. Rep., pp. 1-56, Apr. 2016. Last retrieved on Nov. 26, 2016. [Online]. Available: http:www.irena.org/ DocumentDownloads/Publications/IRENA RE Capacity Statistics 2016.pdf

[2] F. Blaabjerg, D. M. Ionel, Y. Yang, and H. Wang, "Renewable energy systems technology overview and perspectives," in Renewable Energy Devices and Systems with Simulations in MATLAB and ANSYS, F. Blaabjerg and D. M. Ionel, Eds. CRC Press LLC, 2017.

[3] Danish Ministry of Energy, Utilities and Climate, "From coal, oil and gas to green energy," Press Release, Feb. 2011. Last retrieved on Nov. 27, 2016. [Online]. Available: http://old.efkm.dk/en/news/fromcoal-oil-and-gas-to-green-energy

[4] F. Blaabjerg and K. Ma, "Future on power electronics for wind turbine systems," IEEE J. Emerg. Sel. Top. Power Electron., vol. 1, no. 3, pp.139-152, Sept. 2013.

[5] F. Blaabjerg, K. Ma, and Y. Yang, "Power electronics - the key technology for renewable energy systems," in Proc. EVER, pp. 1-11,Mar. 2014.

[6] J. M. Carrasco, L. G. Franquelo, J. T. Bialasiewicz, E. Galvan, R. C.PortilloGuisado, M. A. M. Prats, J. I. Leon, and N. MorenoAlfonso, "Power-electronic systems for the grid integration of renewable energy sources: A survey," IEEE Trans. Ind. Electron., vol. 53, no. 4, pp. 1002-1016, Jun. 2006.

[7] Y. Yang and F. Blaabjerg, "Overview of single-phase grid-connected photovoltaic systems," Electr. Power Compo. Sys., vol. 43, no. 12, pp.1352-1363, 2015 .

[8] J. D. van Wyk and F. C. Lee, "On a future for power electronics," IEEE J. Emerg. Sel. Top. Power Electron., vol. 1, no. 2, pp. 59-72, Jun. 2013.

[9] J. C. Balda and A. Mantooth, "Power-semiconductor devices and components for new power converter developments: A key enabler for ultrahigh efficiency power electronics," IEEE Power Electron. Mag., vol. 3, no. 2,pp. 53-56, Jun. 2016.

[10] F. Blaabjerg, K. Ma, and D. Zhou, "Power electronics and reliability in renewable energy systems," in Proc. ISIE, pp. 19-30, May 2012.

[11] C. Kost, J. N. Mayer, J. Thomsen, N. Hartmann, C. Senkpiel, S. Philipps, S. Nold, S. Lude, N. Saad, and T. Schlegl, "Levelized cost of electricity renewable energy technologies," Tech. Rep., Fraunhofer Institute for Solar Energy Systems ISE, 2013. Last retrieved on Nov. 27, 2016. [Online]. Available: https://www.ise. fraunhofer.de/en/publications/veroeffentlichungen-pdf-dateien-en/ studien-und-konzeptpapiere/study-levelized-cost-of-electricityrenewable-energies.pdf

[12] M. Woodhouse, R. Jones-Albertus, D. Feldman, R. Fu, K. Horowitz, D. Chung, D. Jordan, and S. Kurtz, "The role of advancements in solar photovoltaic efficiency, reliability, and costs," Tech. Rep. (NREL/TP-6A20-65872), National Renewable Energy Laboratory (NREL) of the U.S. Department of Energy, May 2016. Last retrieved on Nov. 27,2016. [Online]. Available: http://www.nrel.gov/docs/ fy16osti/65800.pdf

[13] U.S. Department of Energy (DOE), "Energy department announces more than $90 \%$ achievement of 2020 sunshot goal, sets sights on 2030 affordability targets," Press Release, Nov. 2016. Last retrieved on Nov. 27, 2016. [Online]. Available: https://goo.gl/hhfpfw

[14] Y. Yang, H. Wang, and F. Blaabjerg, "Reliability assessment of transformerless PV inverters considering mission profiles," Int. J. Photoenergy, vol. 2015, pp. 1-10, DOI: 10.1155/2015/968269. 2015.

[15] T. Kerekes, R. Teodorescu, M. Liserre, C. Klumpner, and M. Sumner, "Evaluation of three-phase transformerless photovoltaic inverter topologies," IEEE Trans. Power Electron., vol. 24, no. 9 , pp. 2202-2211, Sept.2009.

[16] S. Kouro, J. I. Leon, D. Vinnikov, and L. G. Franquelo, "Gridconnected photovoltaic systems: An overview of recent research and emerging PV converter technology," IEEE Ind. Electron. Mag., vol. 9, no. 1, pp. 47-61, Mar. 2015.

[17] M. Islam and S. Mekhilef, "Efficient transformerless MOSFET inverter for a grid-tied photovoltaic system," IEEE Trans. Power Electron.,vol. 31, no. 9, pp. 6305-6316, Sept. 2016.

[18] R. Khazaka, L. Mendizabal, D. Henry, and R. Hanna, "Survey of hightemperature reliability of power electronics packaging components," IEEE Trans. Power Electron., vol. 30, no. 5, pp. 2456-2464, May 2015.

[19] J. Colmenares, D. P. Sadik, P. Hilber, and H. P. Nee, "Reliability analysis of a high-efficiency $\mathrm{SiC}$ three-phase inverter," IEEE $J$. Emerg. Sel. Top. Power Electron., vol. 4, no. 3, pp. 996-1006, Sept. 2016.

[20] E. Gurpinar, Y. Yang, F. Iannuzzo, A. Castellazzi, and F. Blaabjerg, "Reliability-driven assessment of GaN HEMTs and Si IGBTs in 3LANPC PV inverters," IEEE J. Emerg. Sel. Top. Power Electron., vol. 4, no. 3, pp. 956-969, Sept. 2016.

[21] B. Burger and D. Kranzer, "Extreme high efficiency PV-power converters," in Proc. EPE - ECCE Europe, Sept. 2009, pp. 1-13.

[22] M. H. Todorovic, F. Carastro, T. Schuetz, R. Roesner, L. Stevanovic, G. Mandrusiak, B. Rowden, F. Tao, P. Cioffi, J. Nasadoski, and R. Datta, "SiC MW PV inverter," in Proc. PCIM Europe, May 2016, pp. 1-8.

[23] Y. Furusho and K. Fujii, "1-MW solar power conditioning system with boost converter using all-SiC power module," in Proc. CIPS, Mar. 2016, pp. 1-5.

[24] L. M. Moore and H. N. Post, "Five years of operating experience at a large, utility-scale photovoltaic generating plant," Prog. Photovolt: Res. Appl., vol. 16, no. 3, pp. 249-259, 2008.

[25] H. Wang, M. Liserre, and F. Blaabjerg, "Toward reliable power electronics: Challenges, design tools, and opportunities," IEEE Ind. Electron. Mag., vol. 7, no. 2, pp. 17-26, Jun. 2013.

[26] H. Wang, M. Liserre, F. Blaabjerg, P. de Place Rimmen, J. B. Jacobsen, T. Kvisgaard, and J. Landkildehus, "Transitioning to physics-of-failure as a reliability driver in power electronics," IEEE J. Emerg. Sel. Top. Power Electron., vol. 2, no. 1, pp. 97-114, Mar. 2014.

[27] S. Yang, A. Bryant, P. Mawby, D. Xiang, L. Ran, and P. Tavner, "An industry-based survey of reliability in power electronic converters," IEEE Trans. Ind. Appl., vol. 47, no. 3, pp. 1441-1451, May 2011.

[28] Y. Song and B. Wang, "Survey on reliability of power electronic systems," IEEE Trans. Power Electron., vol. 28, no. 1, pp. 591-604, Jan. 2013.

[29] S. Yang, D. Xiang, A. Bryant, P. Mawby, L. Ran, and P. Tavner, "Condition monitoring for device reliability in power electronic converters: A review," IEEE Trans. Power Electron., vol. 25, no. 11, pp. 2734-2752, Nov. 2010

[30] H. Oh, B. Han, P. McCluskey, C. Han, and B. D. Youn, "Physicsoffailure, condition monitoring, and prognostics of insulated gate bipolar transistor modules: A review," IEEE Trans. Power Electron., vol. 30, no. 5, pp. 2413-2426, May 2015.

[31] T. Schriefer and M. Hofmann, "Mechanical reliability of power electronic systems," in Proc. CIPS, Mar. 2016, pp. 1-6.

[32] S. V. Dhople, A. Davoudi, A. D. Dom'inguez-Garc' 1a, and P. L. Chapman, "A unified approach to reliability assessment of multiphase dc-dc converters in photovoltaic energy conversion systems," IEEE Trans. Power Electron., vol. 27, no. 2, pp. 739-751, Feb. 2012

[33] L. Yang, P. A. Agyakwa, and C. M. Johnson, "Physics-of-failure 
lifetime prediction models for wire bond interconnects in power electronic modules," IEEE Trans. Device Mat. Rel., vol. 13, no. 1, pp. 9-17, Mar. 2013.

[34] Y. Song and B. Wang, "Evaluation methodology and control strategies for improving reliability of HEV power electronic system," IEEE Trans. Veh. Technol., vol. 63, no. 8, pp. 3661-3676, Oct. 2014.

[35] X. Ma, Y. Guo, L. Wang, and W. Ji, "Exploration of the reliability of automotive electronic power steering system using device junction electrothermal profile cycle," IEEE Access, vol. 4, pp. 7054-7062, Nov. 2016.

[36] Y. Yang, V. S. Sularea, K. Ma, and F. Blaabjerg, "Advanced design tools for the reliability of power electronics - case studies on a photovoltaic (PV) system," in Proc. IECON, Nov. 2015, pp. 28282833.

[37] X. Shi and A. M. Bazzi, "Solar photovoltaic power electronic systems: Design for reliability approach," in Proc. EPE - ECCE Europe, Sept. 2015, pp. 1-8.

[38] U.S. Department of Defense, MIL-HDBK-217F - Military Handbook for Reliability Prediction of Electronic Equipment. Department of Defense, Washington DC, USA, Dec. 1991.

[39] C. Jais, B. Werner, and D. Das, "Reliability predictions - continued reliance on a misleading approach," in Proc. RAMS, Jan. 2013, pp. $1-6$.

[40] M. Aten, G. Towers, C. Whitley, P. Wheeler, J. Clare, and K. Bradley, "Reliability comparison of matrix and other converter topologies," IEEE Trans. Aerosp. Electron. Syst., vol. 42, no. 3, pp. 867-875, Jul. 2006.

[41] R. Burgos, G. Chen, F. Wang, D. Boroyevich, W. G. Odendaal, and J. D. V. Wyk, "Reliability-oriented design of three-phase power converters for aircraft applications," IEEE Trans. Aerosp. Electron. Syst., vol. 48, no. 2, pp. 1249-1263, Apr. 2012.

[42] D. Hirschmann, D. Tissen, S. Schroder, and R. W. D. Doncker, "Reliability prediction for inverters in hybrid electrical vehicles," IEEE Trans. Power Electron., vol. 22, no. 6, pp. 2511-2517, Nov. 2007.

[43] S. E. D. Le'on-Aldaco, H. Calleja, and J. A. Alquicira, "Reliability and mission profiles of photovoltaic systems: A FIDES approach," IEEE Trans. Power Electron., vol. 30, no. 5, pp. 2578-2586, May 2015.

[44] W. S. Lee, D. L. Grosh, F. A. Tillman, and C. H. Lie, "Fault tree analysis, methods, and applications - a review," IEEE Trans. Rel., vol. R-34, no. 3, pp. 194-203, Aug. 1985.

[45] G. R. Biswal, R. P. Maheshwari, and M. L. Dewal, "Cool the generators: System reliability and fault tree analysis of hydrogen cooling systems," IEEE Ind. Electron. Mag., vol. 7, no. 1, pp. 30-40, Mar. 2013.

[46] E. Chatzinikolaou and D. J. Rogers, "A comparison of gridconnected battery energy storage system designs," IEEE Transactions on Power Electronics, vol. PP, no. 99, pp. 1-11, in press, DOI:10.1109/ TPEL.2016.2629020 2016.

[47] A. M. Bazzi, A. Dominguez-Garcia, and P. T. Krein, "Markov reliability modeling for induction motor drives under field-oriented control," IEEE Trans. Power Electron., vol. 27, no. 2, pp. 534-546, Feb. 2012.

[48] H. Chen, H. Yang, Y. Chen, and H. H. C. Iu, "Reliability assessment of the switched reluctance motor drive under single switch chopping strategy," IEEE Trans. Power Electron., vol. 31, no. 3, pp. 23952408, Mar. 2016.

[49] J. Yuan, C. H. Lin, S. J. Chang, and S. H. Lai, "Reliability modeling evaluation for networks under multiple fluctuating operational conditions," IEEE Trans. Rel., vol. R-36, no. 5, pp. 557-564, Dec. 1987.

[50] H. C. Liu, J. X. You, P. Li, and Q. Su, "Failure mode and effect analysis under uncertainty: An integrated multiple criteria decision making approach," IEEE Trans. Rel., vol. 65, no. 3, pp. 1380-1392, Sept. 2016.

[51] S. Haghbin, "Electrical failure mode and effect analysis of a $3.3 \mathrm{~kW}$ onboard vehicle battery charger," in Proc. EPE - ECCE Europe, pp. 1-10, Sept. 2016.

[52] M. “Cepin, "Reliability block diagram," in Assessment of Power System Reliability. Springer, 2011, pp. 119-123.
[53] H. S.-H. Chung, H. Wang, F. Blaabjerg, and M. Pecht, Reliability of Power Electronic Converter Systems. IET, 2015.

[54] J. Flicker, G. Tamizhmani, M. K. Moorthy, R. Thiagarajan, and R. Ayyanar, "Accelerated testing of module-level power electronics for long-term reliability," IEEE J. Photovoltaics, vol. PP, no. 99, pp. 1-9, in press, DOI: 10.1109/JPHOTOV.2016.2621339, 2016.

[55] P. McCluskey, "Reliability of power electronics under thermal loading," in Proc. CIPS, Mar. 2012, pp. 1-8.

[56] W. Lai, M. Chen, L. Ran, O. Alatise, S. Xu, and P. Mawby, "Low tj stress cycle effect in IGBT power module die-attach lifetime modeling," IEEE Trans. Power Electron., vol. 31, no. 9, pp. 6575 6585, Sept. 2016

[57] T. Lei, M. Barnes, S. Smith, S. h. Hur, A. Stock, and W. E. Leithead, "Using improved power electronics modeling and turbine control to improve wind turbine reliability," IEEE Trans. Energy Conversion, vol. 30, no. 3, pp. 1043-1051, Sept. 2015.

[58] S. Russo, A. Testa, S. D. Caro, T. Scimone, S. Panarello, S. Patan, G. Scelba, and G. Scarcella, "Reliability assessment of power MOSFETs working in avalanche mode based on a thermal strain direct measurement approach," IEEE Trans. Ind. Appl., vol. 52, no. 2 , pp. 1688-1697, Mar. 2016.

[59] H. Li, X. Liao, Z. Zeng, Y. Hu, Y. Li, S. Liu, and L. Ran, "Thermal coupling analysis for a multi-chip paralleled IGBT module in a doubly fed wind turbine power converter," IEEE Trans. Energy Conversion, vol. PP, no. 99, pp. 1-11, in press, DOI: 10.1109 / TEC.2016.2614526, 2016

[60] V. Smet, F. Forest, J. J. Huselstein, F. Richardeau, Z. Khatir, S. Lefebvre, and M. Berkani, "Ageing and failure modes of IGBT modules in hightemperature power cycling," IEEE Trans. Ind. Electron., vol. 58, no. 10, pp. 4931-4941, Oct. 2011.

[61] U. Scheuermann, R. Schmidt, and P. Newman, "Power cycling testing with different load pulse durations," in Proc. PEMD, Apr. 2014, pp. 1-6.

[62] P. D. Reigosa, H. Wang, Y. Yang, and F. Blaabjerg, "Prediction of bond wire fatigue of IGBTs in a PV inverter under a long-term operation," IEEE Trans. Power Electron., vol. 31, no. 10, pp. 71717182 , Oct. 2016.

[63] H. Huang and P. A. Mawby, "A lifetime estimation technique for voltage source inverters," IEEE Trans. Power Electron., vol. 28, no. 8, pp. 4113-4119, Aug. 2013.

[64] L. R. GopiReddy, L. M. Tolbert, and B. Ozpineci, "Power cycle testing of power switches: A literature survey," IEEE Trans. Power Electron., vol. 30, no. 5, pp. 2465-2473, May 2015.

[65] Y. S. Lai, T. H. Wang, and C. C. Lee, "Thermal-mechanical coupling analysis for coupled power- and thermal-cycling reliability of boardlevel electronic packages," IEEE Trans. Device Mat. Rel., vol. 8, no. 1, pp. 122-128, Mar. 2008.

[66] N. Wang, I. Cotton, and K. Evans, "Impact of thermal cycling in humid environments on power electronic modules," IEEE Trans. Comp., Packag., Manufact. Technol., vol. 2, no. 7, pp. 1085-1091, Jul. 2012.

[67] H. Luo, Y. Chen, P. Sun, W. Li, and X. He, "Junction temperature extraction approach with turn-off delay time for high-voltage highpower IGBT modules," IEEE Trans. Power Electron., vol. 31, no. 7, pp. 5122-5132, Jul. 2016.

[68] M. A. Eleffendi and C. M. Johnson, "Application of Kalman filter to estimate junction temperature in IGBT power modules," IEEE Trans. Power Electron., vol. 31, no. 2, pp. 1576-1587, Feb. 2016.

[69] N. Baker, M. Liserre, L. Dupont, and Y. Avenas, "Improved reliability of power modules: A review of online junction temperature measurement methods," IEEE Ind. Electron. Mag., vol. 8, no. 3, pp. 17-27, Sept. 2014.

[70] K. Ma, M. Liserre, and F. Blaabjerg, "Reactive power influence on the thermal cycling of multi-mw wind power inverter," IEEE Trans. Ind. Appl., vol. 49, no. 2, pp. 922-930, Mar. 2013.

[71] K. Ma and F. Blaabjerg, "Modulation methods for three-level neutralpoint-clamped inverter achieving stress redistribution under moderate modulation index," IEEE Trans. Power Electron., vol. 31, no. 1 , pp. 5-10, Jan. 2016.

[72] D. A. Murdock, J. E. R. Torres, J. J. Connors, and R. D. Lorenz, "Active thermal control of power electronic modules," IEEE Trans. 
Ind. Appl., vol. 42, no. 2, pp. 552-558, Mar. 2006.

[73] S. E. D. Leon-Aldaco, H. Calleja, F. Chan, and H. R. JimenezGrajales, "Effect of the mission profile on the reliability of a power converter aimed at photovoltaic applications - a case study," IEEE Trans. Power Electron., vol. 28, no. 6, pp. 2998-3007, Jun. 2013.

[74] K. Ma, M. Liserre, F. Blaabjerg, and T. Kerekes, "Thermal loading and lifetime estimation for power device considering mission profiles in wind power converter," IEEE Trans. Power Electron., vol. 30, no. 2, pp. 590-602, Feb. 2015.

[75] M. Musallam, C. Yin, C. Bailey, and M. Johnson, "Mission profilebased reliability design and real-time life consumption estimation in power electronics," IEEE Trans. Power Electron., vol. 30, no. 5, pp. 2601-2613, May 2015.

[76] Y. Yang, H. Wang, F. Blaabjerg, and K. Ma, "Mission profile based multi-disciplinary analysis of power modules in single-phase transformerless photovoltaic inverters," in Proc. EPE - ECCE Europe, Sept. 2013, pp. 1-10.

[77] N. A. Rahim, R. Saidur, K. H. Solangi, M. Othman, and N. Amin, "Survey of grid-connected photovoltaic inverters and related systems," Clean Technol. Environ. Policy, vol. 14, no. 4, pp. 521533, 2012.

[78] B. Xiao, L. Hang, J. Mei, C. Riley, L. M. Tolbert, and B. Ozpineci, "Modular cascaded H-bridge multilevel PV inverter with distributed MPPT for grid-connected applications," IEEE Trans. Ind. Appl., vol. 51, no. 2, pp. 1722-1731, Mar. 2015.

[79] M. R. Islam, Y. Guo, and J. Zhu, "A multilevel medium-voltage inverter for step-up-transformer-less grid connection of photovoltaic power plants," IEEE J. Photovoltaics, vol. 4, no. 3, pp. 881-889, May 2014.

[80] H. Nademi, A. Das, R. Burgos, and L. E. Norum, "A new circuit performance of modular multilevel inverter suitable for photovoltaic conversion plants," IEEE J. Emerg. Sel. Top. Power Electron., vol. 4, no. 2, pp. 393-404, Jun. 2016.

[81] D. Sera, R. Teodorescu, and P. Rodriguez, "PV panel model based on datasheet values," in Proc. ISIE, pp. 2392-2396, Jun. 2007.

[82] H. Huang and P. A. Mawby, "A lifetime estimation technique for voltage source inverters," IEEE Trans. Power Electron., vol. 28, no. 8, pp. 4113-4119, Aug. 2013

[83] I. F. Kovacevic, U. Drofenik, and J. W. Kolar, "New physical model for lifetime estimation of power modules," in Proc. IPEC - ECCE ASIA, Jun. 2010, pp. 2106-2114.

[84] Y. Shen, H. Wang, Y. Yang, P. D. Reigosa, and F. Blaabjerg, "Mission profile based sizing of IGBT chip area for PV inverter applications," in Proc. PEDG, Jun. 2016, pp. 1-8.

[85] D. Zhou, H. Wang, F. Blaabjerg, S. K. Kaer, and D. Blom-Hansen, "System-level reliability assessment of power stage in fuel cell application," in Proc. ECCE, Sept. 2016, pp. 1-8.

[86] ZVEI, "How to measure lifetime for robustnesss validation - step by step," Rev. 1.9, Nov. 2012.

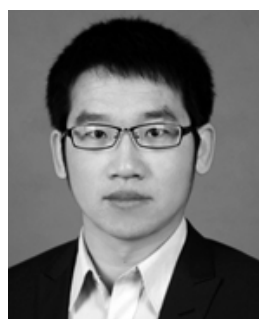

Yongheng Yang received the B.Eng. degree in Electrical Engineering and Automation from Northwestern Polytechnical University, Xi'an, China, in 2009, and the Ph.D. degree in Electrical Engineering from Aalborg University, Aalborg, Denmark, in 2014

He was a postgraduate at Southeast University, China, from 2009 to 2011. In 2013, he was a Visiting Scholar at Texas A\&M University, USA.
Since 2014, he has been with the Department of Energy Technology, Aalborg University, where currently he is an Assistant Professor. His research is focused on grid integration of renewable energy systems, power converter design, analysis and control, harmonics identification and mitigation, and reliability in power electronics. Dr. Yang has published more than 80 technical papers and co-authored a book - Periodic Control of Power Electronic Converters (London, UK: IET, 2017).

Dr. Yang is a Member of the IEEE Power Electronics Society (PELS) Students and Young Professionals Committee. He served as a Guest Associate Editor of IEEE JOURNAL OF EMERGING AND SELECTED TOPICS IN POWER ELECTRONICS, and has also been invited as a Guest Editor of Applied Sciences. He is an active reviewer for relevant top-tier journals.

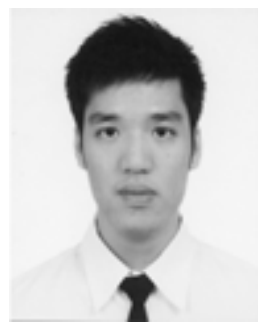

Ariya Sangwongwanich was born in Bangkok, Thailand, in 1991. He received the B.Eng. degree in Electrical Engineering from Chulalongkorn University, Thailand, in 2013, and the M.Sc. in Energy Engineering from Aalborg University, Denmark, in 2015, where he is currently working as a research assistant. His research interests include control of grid-connected converter, photovoltaic systems, and high-power modular multilevel converters.

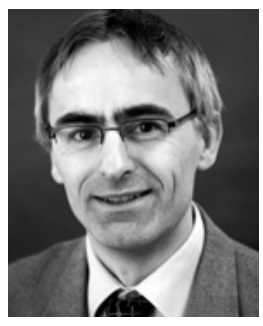

Frede Blaabjerg was with ABB-Scandia, Randers, Denmark, from 1987 to 1988 . From 1988 to 1992 , he was a Ph.D. Student with Aalborg University, Aalborg, Denmark. He became an Assistant Professor in 1992, Associate Professor in 1996, and Full Professor of power electronics and drives in 1998. His current research interests include power electronics and its applications such as in wind turbines, PV systems, reliability, harmonics and adjustable speed drives.

He has received 18 IEEE Prize Paper Awards, the IEEE PELS Distinguished Service Award in 2009, the EPE-PEMC Council Award in 2010, the IEEE William E. Newell Power Electronics Award 2014 and the Villum Kann Rasmussen Research Award 2014. He was an Editor-in-Chief of the IEEE TRANSACTIONS ON POWER ELECTRONICS from 2006 to 2012. He was nominated in 2014, 2015 and 2016 by Thomson Reuters to be between the most 250 cited researchers in Engineering in the world. 